\title{
The Clinical and Economic Implications of Drug Utilization Patterns in the Treatment of Hypertension with ACE Inhibitors and Calcium Channel Blockers in a Managed Care Setting
}

\author{
Marcus Wilson, John Patwell, Omar Shoheiber, Diana Brixner, Jeffrey Kalmanowicz, and Jessica Eicher
}

\begin{abstract}
Hypertension is the number one reason for visits to a physician, accounting for roughly one in 10 visits. Despite extensive expenditures on the disease, only $20 \%$ of patients are well controlled. This longitudinal patient review (LPR) analysis was performed as an initial step in modeling the impact of unsuccessful outcomes in patients whose initial treatment was either an angiotensin converting enzyme inhibitor (ACEI) or a calcium channel blocker (CCB) as first-line pharmacologic therapy. In addition, the cost impact of these changes was measured pre- and post-modification in terms of pharmacy costs per member per month (PMPM).

The study was conducted by retrospectively analyzing pharmacy claims data from six managed care plans of multiple design. The outcomes measured were the number, type, and first-year acquisition cost of modifications of an antihypertensive drug (AD) in compliant, newly diagnosed hypertensive patients initiated on either an ACEl or CCB.

Over the initial 12 months of therapy, $44 \%$ ( $41 \%$ and $46 \%$ for the ACEI and CCBs, respectively) had at least one modification to their AD therapy. The most frequent modification type for the ACEI was an increase in dose $(40 \%)$ and, for the CCB, the addition of a new class of drug $(25 \%)$. The most common drug added to an ACEI was a CCB ( $60 \%$ of additions) and the most common drug added to a CCB was an ACEl (49\% of additions).
\end{abstract}

The first-year acquisition cost (FAC) for patients with no modification was $\$ 322$ and $\$ 427$ for ACEI and CCB, respectively. In both groups, as the number of modifications increased, the FAC increased. The range was $\$ 391-\$ 880$ for the ACEI group and $\$ 496-\$ 861$ for the CCB group for one to six modifications.

The analysis demonstrated that in compliant patients FAC increases with the increase in number of modifications to $A D$ therapy, and the FAC and the need for subsequent modifications to therapy vary between modification types. It also suggests that a dosage increase or the addition of a CCB to an ACEl or ACEl to a CCB is more successful in terms of lesser need for subsequent modifications to therapy. The highest FAC is associated with the addition of a new drug class to the initial therapy. The PMPM cost increased post-modification in all groups. These results imply that total medical costs also would be increased as the frequency of modification increases. These data help lay the foundation for the development of a larger economic model for hypertension.

KEY WORDS: Hypertension, Economics, Managed care, ACE Inhibitor, Calcium channel blocker, Economic model

J Managed Care Pharm 1998; 4: 194-202

$\mathrm{T}$ he prevalence of hypertension in society is high. In the United States, $20 \%$, or about 50 million people, have the disease. ${ }^{1}$ The financial burden of the disease is staggering. The costs to society in 1997 are estimated to have been $\$ 30$ billion, of which $\$ 21.8$ billion are due to direct costs such as hospitalizations and physician visits. ${ }^{2}$ Antihypertensive drugs (ADs) account for nearly one-third of the total direct costs ( $\$ 7$ billion). ${ }^{2}$ Despite the resources expended on hypertension, less than $25 \%$ of patients are well controlled. ${ }^{\prime}$

Because of the high cost of treating hypertension and the poor results, the health care community is rigorously debating the impact of unsuccessful outcomes in these patients. Health care providers are concerned not only about long-term costs but also about continual costs that are incurred from the time of diagnosis. In order to evaluate this issue as well as measure the impact of disease management programs on these costs, baseline and impact assessment systems need to be designed and implemented in the managed care setting. A critical aspect of these needed systems is the development of sound. economic models of hypertension treatment in naturalistic settings. 
A useful initial step in this model-building process is the retrospective evaluation of claims data. Because pharmacy claims are more complicated and generally more reliable than other medical claims, the LPR process is being used as the initial technique for this analysis. The purpose of this LPR was to provide $\mathrm{AD}$ utilization and cost analysis data that are useful for designing a prospective effectiveness and costimpact protocol for use in managed care and disease management programs, as recommended by prior investigators. ${ }^{4}$ Specifically, the authors are interested in determining: 1) the patterns of AD therapy modifications after the initiation of either an angiotensin converting enzyme inhibitor (ACEI) or a calcium channel blocker (CCB) for first-line pharmacological therapy, and 2) the potential costs of each of these choices.

The data derived from pharmacy claims were utilized to describe modification patterns after the initiation of $A D$ therapy. The types of modifications suggest the categorization of the reasons for initial $\mathrm{AD}$ failure and can lead to suggestions for improving treatment protocols or better patient outcomes, or for targeting potential areas for cost savings. An estimate as to the frequency of these events is necessary in the hypertension economic modeling process.

ACEI and CCB were chosen for analysis for three reasons:

$\Delta$ their popularity among prescribers;

$\Delta$ the high drug costs associated with their use as compared to other classes of $\mathrm{AD}$; and

$\Delta$ the new combination $\mathrm{ACEV} / \mathrm{CCB}$ products entering the AD market.

Additionally, while their efficacy and safety data are compelling, little is known about the effectiveness of these products when utilized in a naturalistic environment. The authors hypothesized that there are incremental costs of ADs for patients not achieving satisfactory outcomes and that these increases occur within months, rather than years. For the purpose of interpretation of these data, satisfactory outcomes are defined as a reduction in blood pressure to target levels, with tolerable adverse events.

\section{STUDY DESIGN/METHODOLOGY}

A separate analysis and review of drug utilization was conducted across six managed care organizations (MCOs) throughout the United States. The data collected represent staff-, group-, independent practice association (IPA)-, network-, and mixed-model HMOs. Participants included patients who began treatment for hypertension with an ACEI or a CCB therapy during 1993 and continued on any antihypertensive therapy through December 31, 1994. Patients were identified as "first starts" on an ACEI or a CCB if they began such treatment in 1993. In order to determine first starts, a retrospective analysis was performed, in which the MCO's medications days supply data were collected from plans on all of their antihypertensive patients. In each plan, the days supply for medication was either a 30 - or 60 -day supply. The days supply plus 30 days was the time frame observed retrospectively to determine whether a patient was a first start on an $\mathrm{AD}$ or a new prescription was being filled for existing therapy. For example, if a plan's days supply was for 30 days, the data were examined for a period of 60 days, (days supply plus 30 days) prior to the time when the new prescription was filled. If a patient had no record of receiving $\mathrm{AD}$ within that 60-day period, the patient was assumied to be a first start. Patients with $80 \%$ or greater compliance using medication pos-session ratio (MPR) with $\mathrm{AD}$ therapy were included in the analysis.

Any change in $\mathrm{AD}$ therapy over the 12-month study period was considered a modification. Each modification in $\mathrm{AD}$ therapy was classified into one of the following categories:

$\Delta$ Increased Dose - any adjustment in dose resulting in an increase in the total daily dose.

$\Delta$ Decreased Dose - any adjustment in dose resulting in a decrease in the total daily dose.

$\Delta$ Added Drug (New Class) - the addition of any AD from a different therapeutic class.

$\Delta$ Added Drug (Same Class) - the addition of any AD from within the same therapeutic class. For the purpose of this analysis, all calcium channel blockers were considered to be in the same class.

$\Delta$ Switched Formulation - any change in product formulation.

A Switched Within Class - any switch in drug to an $\mathrm{AD}$ within the same therapeutic class.

Switched Class - any switch in drug to an AD from a different therapeutic class.

A Dropped Drug - any discontinuation of an AD during the study period.

\section{PATIENT SELECTION}

All study participants had a diagnosis of hypertension by International Classification of Disease 9th Revision (ICD-9) coding. Patients having a diagnosis of congestive heart failure $(\mathrm{CHF})$ and/or angina pectoris were excluded from the study. Those whose antihypertensive therapy was discontinued before 12 months of continuous therapy, or who had disenrolled from the plan for any reason, also were excluded. A patient was assumed to have discontinued his or her medication if the period between refills exceeded the period of time for the respective MCO's days supply plus 30 .

\section{DATA MEASUREMENTS}

Cost data were collected from all plans for the first year of therapy. Data from the pharmacy claims, such as drug name, 
formulation, strength; fill dates, and acquisition costs, were used to determine therapeutic episodes of care. Therapeutic episodes of care were defined as periods of consistent medication use. Any change in drug, addition of drug, or deletion of drug was defined as a modification to therapy and thus a new episode of care. Descriptive statistics were calculated on costs, number of modifications, and time span between modifications. Costs were defined as the average wholesale price (AWP) discounted by $10 \%$. For consistency across the MCOs, dispensing fees were not added to the cost formula, nor were differential discounts or other negotiated pricing elements considered.

\section{RESULTS}

\section{Frequency of Modifications}

A total of 1,932 patients started antihypertensive therapy with an ACEl or CCB in 1993 and met the other inclusion/ exclusion criteria. Of these, 936 (48\%) initiated therapy with an ACEI, and 996 (52\%) initiated therapy with a CCB. During the subsequent 12 months, $44 \%$ of these patients required at least one modification in drug therapy $(41 \%$ and $46 \%$ for ACEI and CCB, respectively).

There were 1,308 modifications made during the 12 months following initiation of drug therapy-580 and 728 for the ACEI and CCB groups, respectively. The modification rate per 1,000 patients started on an AD drug was 620 (580 per 936 patients) and 731 (728 per 996 patients) for the ACEI and the CCB groups, respectively. There were up to six modifications made during the 12-month follow-up in each group.

\section{Type of Modification}

The frequency of each type of first modification per group is outlined in Table 1. Of patients requiring a modification, the most common first modification for the ACEI was an Increased Dose (40\%), followed by Switched Class (27\%) and Added Drug (New Class) (21\%). For CCBs the most common first modification was Added Drug (New Class) (25\%), followed closely by Increased Dose (23\%) and Switched Class (20\%).

Table 1 shows the distribution of the first two modifications by type of modification. There was a difference in ranking of the type of modification between the first and second modifications. While an Increased Dose was the most common change for first modification in the ACEI group (40\%), the preferred second modification was Switched Class (37\%). In the $\mathrm{CCB}$ group, the ranking for the second modification was similar to the first modification: Switched Class (28\% versus $20 \%$ ), Increased Dose ( $27 \%$ versus $23 \%$ ), and Added Drug (New Class) (23\% versus 25\%). Further stratification of subsequent modifications resulted in numbers too small to draw conclusions from. The most common drug added to the $\mathrm{AD}$ in the Added Drug (New Class) category was from the other class (i.e., a CCB added to an ACEI or vice versa) as shown in Table 2 . This occurred in $61 \%$ of additions to the

\section{Table 1. Frequency of Modifications}

\begin{tabular}{|c|c|c|c|c|c|}
\hline \multirow[t]{2}{*}{ Initial Therapy Class } & \multirow[t]{2}{*}{ Event } & \multicolumn{2}{|c|}{ First Modification } & \multicolumn{2}{|c|}{ Second Modification } \\
\hline & & $\mathrm{n}$ & $\%$ & $\mathrm{n}$ & $\%$ \\
\hline \multirow{4}{*}{$\cdot \cdot$} & Increased dose & 153 & $40 \%$ & 38 & $29 \%$ \\
\hline & Decreased dose & 31 & $8 \%$ & 2 & $2 \%$ \\
\hline & Added drug (new class) & 79 & $21 \%$ & 17 & $13 \%$ \\
\hline & Added drug (same class) & 3 & $1 \%$ & 3 & $2 \%$ \\
\hline \multirow[t]{5}{*}{ ACEI } & Switched formulation & 0 & $0 \%$ & 3 & $2 \%$ \\
\hline & Switched within class & 14 & $4 \%$ & 12 & $9 \%$ \\
\hline & Switched class & 102 & $27 \%$ & 48 & $37 \%$ \\
\hline & Dropped drug & 0 & $0 \%$ & 8 & $6 \%$ \\
\hline & Total & 382 & $100 \%$ & 131 & $100 \%$ \\
\hline
\end{tabular}

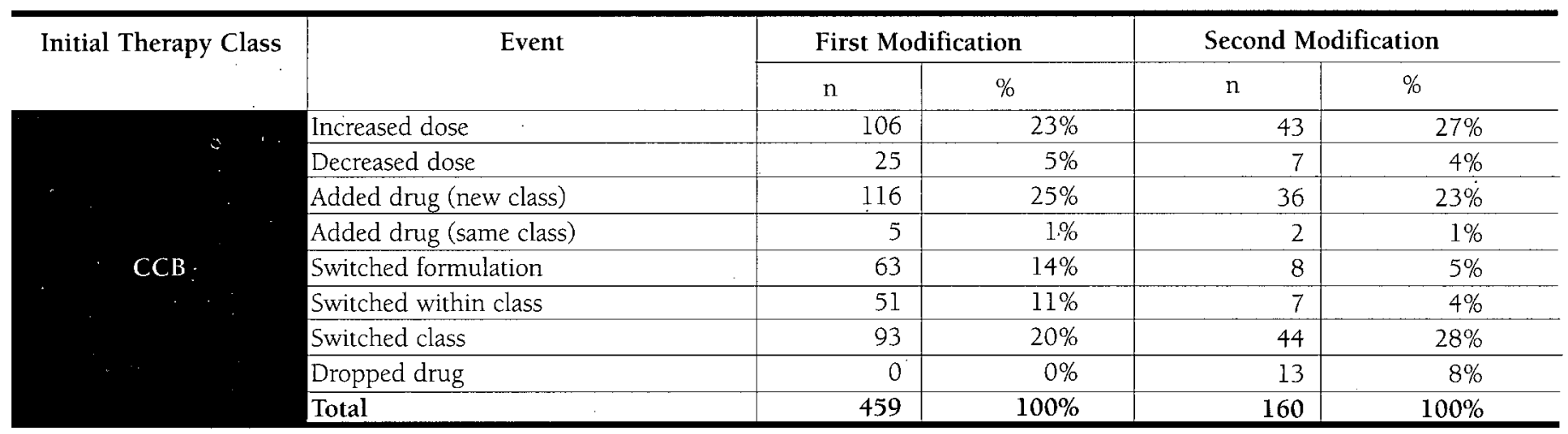


ACEI group and $49 \%$ of the CCB group. The second most common drug added to either class was a beta blocker (19\% and $26 \%$ for the ACEI and CCB groups, respectively).

\section{Timing of Modification}

The median time until the first modification in antihypertensive therapy was 81 and 87 days for the ACEI and CCB groups, respectively (Table 3 ). The ranges in the medians were 30-193 days for the ACEI group and 30-141 for the CCB group, depending on the type of modification made. Those patients for whom the first modification was the addition of a drug had the lowest median time to change for both groups. Excluding those categories with an $\mathrm{n}<30$, the highest median time for the ACEI group was for those patients switching class, whereas the highest median time for the $\mathrm{CCB}$ group was for those patients switching formulation.

The aggregate modifications over the first 12 months of therapy for all modification types are displayed in Table 5. Over $50 \%$ of all modifications were done by the third month of therapy for those patients started on an ACEI or a CCB.

\section{First-Year Acquisition Cost (FAC)}

The first-year acquisition costs (FACs) for patients with no modifications were $\$ 322$ and $\$ 427$ for the ACEI and CCB groups, respectively. The FAC increased as the number of modifications increased. Table 4 illustrates the increase of annual costs and the number of prescription refills as modifications were made. The range was $\$ 391-\$ 880$ for the ACEI group and $\$ 496-\$ 861$ for the CCB group for one to six modifications. The highest costs were associated with patients having the highest number of modifications.

Excluding those categories with an $n<30$, Increased Dose resulted in the lowest FAC for the ACEI group (\$357), while Switched Class was the lowest in the CCB group (\$384), as seen in Table 3. In all cases, patients requiring modification in $\mathrm{AD}$ therapy had an increase in AD costs. The one exception was those requiring the Switched Class modification in the $\mathrm{CCB}$ group in which the FAC declined versus those with no modification ( $\$ 384$ versus $\$ 427$ ).

The highest FAC occurred in the modification type Added Drug (New Class), $\$ 670$ and $\$ 733$ for the ACEI and CCB groups, respectively. As stated earlier, the most common addition to an ACEI was a CCB and the most common addition to a CCB was an ACEI. As expected, these groups had the highest FAC of any group ( $\$ 809$ and $\$ 806$ for the ACEV/CCB and $C C B / A C E I$ groups, respectively). Of note, the addition of an alpha blocker to a CCB resulted in the highest acquisition cost, but the number of patients in this category (7) was too small for the results to be reliable.

\section{Costs Per Member Per Month}

The costs per member per month (PMPM) were evaluated both pre- and post-modification (see Table 6 ). The highest average cost increase PMPM of $90 \%$ ( $\$ 29$ to $\$ 55$ ) occurred when adding a new class of drug to the ACEI. This differed for the CCB group with a $77 \%$ increase in cost PMPM ( $\$ 27$ to $\$ 48$ ) when increasing the dose of the CCB. The second most common increase in PMPM ( $\$ 39$ to $\$ 59$ ) was seen when adding a new class of drugs to the CCB (51\%).

\section{DISCUSSION}

The clinical goals for the treatment of the patient with hypertension generally are reducing blood pressure to a

Table 2. Added New Drug Analysis by Class

\begin{tabular}{|c|c|c|c|c|c|c|}
\hline $\begin{array}{c}\text { Initial Therapy } \\
\text { Class }\end{array}$ & Event & $\begin{array}{l}\text { Patient Totals } \\
\text { (n) }\end{array}$ & $\begin{array}{l}\text { Mean Time for } \\
\text { First Modification } \\
\text { (days) }\end{array}$ & $\begin{array}{c}\text { Median Time for } \\
\text { First Modification } \\
\text { (days) }\end{array}$ & Mean $\mathbf{R x} \$$ & Median Rx \$ \\
\hline \multirow{5}{*}{ ACEI } & Added beta blocker & 15 & 77 & 76 & $\$ 449$ & $\$ 354$ \\
\hline & Added CCB & 48 & 59 & 23 & $\$ 809$ & $\$ 698$ \\
\hline & Added diuretic & 9 & 49 & 30 & $\$ 355$ & $\$ 343$ \\
\hline & Added other & 7 & & & & \\
\hline & Total & 79 & 60 & 30 & $\$ 670$ & $\$ 606$ \\
\hline
\end{tabular}

\begin{tabular}{|c|c|c|c|c|c|c|}
\hline $\begin{array}{c}\text { Initial Therapy } \\
\text { Class }\end{array}$ & Event & $\begin{array}{l}\text { Patient Totals } \\
\text { (n) }\end{array}$ & $\begin{array}{l}\text { Mean Time for } \\
\text { First Modification } \\
\text { (days) }\end{array}$ & $\begin{array}{c}\begin{array}{c}\text { Median Time for } \\
\text { First Modification } \\
\text { (days) }\end{array} \\
\end{array}$ & Mean Rx \$ & Median Rx $\$$ \\
\hline \multirow{7}{*}{$\mathrm{CCB}$} & Added ACEI & 57 & 76 & 38 & $\$ 806$ & $\$ 726$ \\
\hline & Added alpha blocker & 7 & 45 & 31 & $\$ 854$ & $\$ 828$ \\
\hline & Added alpha 2 agonist & 6 & 57 & 30 & $\$ 728$ & $\$ 695$ \\
\hline & Added beta blocker & 30 & 46 & 22 & $\$ 695$ & $\$ 688$ \\
\hline & Added diuretic & 10 & 84 & 77 & $\$ 494$ & $\$ 483$ \\
\hline & Added other & 5 & & & & \\
\hline & Total & 116 & 66 & 30 & $\$ 733$ & $\$ 678$ \\
\hline
\end{tabular}


desired value (target blood pressure), maintaining or improving patient quality of life, satisfying the patient's personal need for care, and, ultimately, reducing morbidity and mortality. These goals vary for each physician and each patient. One could assume, when no modifications are made to the compliant patient's drug regimen over time, that the patient is more likely to have achieved most, if not all, of the immediate clinical goals. It also can be assumed, in most cases, that a modification in AD therapy is an indicator that a clinical goal has not been met. Three factors that likely account for the majority of modifications are: 1) failure to achieve target blood pressure; 2) an adverse event; and 3) cost of drug therapy to the plan and/or patient. These assumptions, however, cannot be verified using only pharmacy claims data.
In the present study, as the number of modifications increased, the FAC increased. Additionally, the number of primary care physician (PCP) visits needed to care for these patients is likely to be higher than for those patients requiring no modification in their regimen, consequently increasing associated medical costs as well. This, however, must be confirmed using integrated pharmacy and medical claims data.

Increasing the dose of the $\mathrm{AD}$ is considered the most logical next step for these patients, especially for those drugs having a strong dose-response relationship (e.g., the calcium channel blockers). Clinically, one would be anticipate that the better the dose-response relationship the more likely that increasing the dose would achieve satisfactory outcome, and the less likely the need for further titration in therapy.

Table 3. Initial Modification Type Frequency and Associated Antihypertensive Drug Costs

\begin{tabular}{|c|c|c|c|c|c|c|c|c|c|c|c|c|c|c|c|}
\hline \multirow{2}{*}{$\begin{array}{l}\text { Initial } \\
\text { Therapy } \\
\text { Class }\end{array}$} & \multirow[t]{2}{*}{ Event } & \multicolumn{2}{|c|}{ Patient Totals } & \multicolumn{3}{|c|}{$\begin{array}{c}\text { First Year } \\
\text { Acquisition Costs } \\
\end{array}$} & \multicolumn{3}{|c|}{ Refill Averages } & \multicolumn{3}{|c|}{ Modification Averages } & \multicolumn{3}{|c|}{$\begin{array}{l}\text { Days to First } \\
\text { Modification }\end{array}$} \\
\hline & & $\mathrm{n}$ & $\%$ & $\underset{\$}{\text { Mean } R x}$ & Median \$ & SD & Mean & Median & SD & Mean & Median & SD & Mean & Median & SD \\
\hline \multirow{10}{*}{ ACEI } & No modification & 554 & $59.2 \%$ & $\$ 322$ & $\$ 281$ & $\$ 159$ & 11.24 & 12.00 & 2.13 & 0.00 & 0.00 & 0.00 & 0 & 0 & 0 \\
\hline & Increased dose & 153 & $16.3 \%$ & $\$ 357$ & $\$ 315$ & $\$ 176$ & 11.88 & 12.00 & 3.1.1. & 1.33 & 1.00 & 0.67 & 122 & 89 & 98 \\
\hline & Decreased dose & 31 & $3.3 \%$ & $\$ 379$ & $\$ 297$ & $\$ 220$ & 11.90 & 12.00 & 4.17 & 1.43 & 1.00 & 0.72 & 127 & 98 & 108 \\
\hline & $\begin{array}{l}\text { Added drug } \\
\text { (new class) }\end{array}$ & 79 & $8.4 \%$ & $\$ 670$ & $\$ 606$ & $\$ 395$ & 17.81 & 18.00 & 5.25 & 1.61 & 1.00 & 0.95 & 60 & 30 & 65 \\
\hline & $\begin{array}{l}\text { Added drug } \\
\text { (same class) }\end{array}$ & 3 & $0.3 \%$ & $\$ 275$ & $\$ 248$ & $\$ 158$ & 13.67 & 13.00 & 3.06 & 1.33 & 1.00 & 0.58 & 139 & 193 & 111 \\
\hline & Switched formulation & 0 & $0.0 \%$ & $\$ 0$ & $\$ 0$ & $\$ 0$ & 0.00 & 0.00 & 0.00 & 0.00 & 0.00 & 0.00 & 0 & 0 & 0 \\
\hline & $\begin{array}{l}\text { Switched within } \\
\text { class }\end{array}$ & 14 & $1.5 \%$ & $\$ 331$ & $\$ 312$ & $\$ 162$ & 9.71 & 11.00 & 3.07 & 1.14 & 1.00 & 0.36 & 159 & 151 & 94 \\
\hline & Switched class & 102 & $10.9 \%$ & $\$ 402$ & $\$ 361$ & $\$ 199$ & 12.02 & 12.00 & 4.13 & 1.81 & 1.00 & 1.32 & 141 & 109 & 107 \\
\hline & $\begin{array}{l}\text { Total modification } \\
\text { group }\end{array}$ & 382 & $40.8 \%$ & $\$ 434$ & $\$ 342$ & $\$ 273$ & 13.08 & 13.00 & 4.67 & 1.52 & 1.00 & 0.89 & 116 & 81 & 100 \\
\hline & Total ACE group & 936 & 100.0 & $\$ 368$ & $\$ 303$ & $\$ 220$ & 11.99 & 12.00 & 3.52 & 0.62 & 0.00 & 0.94 & 47 & 0 & 85 \\
\hline
\end{tabular}

\begin{tabular}{|c|c|c|c|c|c|c|c|c|c|c|c|c|c|c|c|}
\hline \multirow{2}{*}{$\begin{array}{l}\text { Initial } \\
\text { Therapy } \\
\text { Class }\end{array}$} & \multirow[t]{2}{*}{ Event } & \multicolumn{2}{|c|}{ Patient Totals } & \multicolumn{3}{|c|}{$\begin{array}{c}\text { First Year } \\
\text { Acquisition Costs }\end{array}$} & \multicolumn{3}{|c|}{ Refill Averages } & \multicolumn{3}{|c|}{ Modification Averages } & \multicolumn{3}{|c|}{$\begin{array}{l}\text { Days to First } \\
\text { Modification }\end{array}$} \\
\hline & & n & $\%$ & $\begin{array}{c}\text { Mean } \mathrm{Rx} \\
\$\end{array}$ & Median $\$$ & SD & Mean & Median & SD & Mean & Median & $\mathrm{SD}$ & Mean & Median & SD \\
\hline \multirow{10}{*}{$\mathrm{CCB}$} & No modification & 537 & $53.9 \%$ & $\$ 427$ & $\$ 414$ & $\$ 186$ & 10.60 & 12.00 & 2.90 & 0.00 & 0.00 & 0.00 & 0 & 0 & 0 \\
\hline & Increased dose & 106 & $10.6 \%$ & $\$ 527$ & $\$ 484$ & $\$ 204$ & 12.24 & 12.00 & 3.54 & 1.43 & 1.00 & 0.92 & 132 & 108 & 107 \\
\hline & Decreased dose & 25 & $2.5 \%$ & $\$ 465$ & $\$ 436$ & $\$ 252$ & 10.76 & 11.00 & 3.24 & 1.44 & 1.00 & 1.65 & 160 & $141^{\circ}$ & 98 \\
\hline & $\begin{array}{l}\text { Added drug } \\
\text { (new class) }\end{array}$ & 116 & $11.6 \%$ & $\$ 733$ & $\$ 678$ & $\$ 335$ & 19.14 & 19.00 & 6.66 & 1.61 & 1.00 & 1.06 & 66 & 30 & 76 \\
\hline & $\begin{array}{l}\text { Added drug } \\
\text { (same class) }\end{array}$ & 5 & $0.5 \%$ & $\$ 539$ & $\$ 427$ & $\$ 182$ & 12.40 & 13.00 & 1.52 & 1.00 & 1.00 & 0.00 & 93 & 44 & 129 \\
\hline & Switched formulation & 63 & $6.3 \%$ & $\$ 452$ & $\$ 453$ & $\$ 194$ & 11.44 & 12.00 & 3.89 & 1.43 & 1.00 & 0.86 & 140 & 121 & 107 \\
\hline & $\begin{array}{l}\text { Switched within } \\
\text { class }\end{array}$ & 51 & $5.1 \%$ & $\$ 483$ & $\$ 444$ & $\$ 250$ & 12.02 & 12.00 & 4.05 & 1.76 & 1.00 & 1.16 & 135 & 100 & 104 \\
\hline & Switched class & 93 & $9.3 \%$ & $\$ 384$ & $\$ 329$ & $\$ 253$ & 12.34 & 12.00 & 6.26 & 1.80 & 1.00 & 1.00 & 145 & 112 & 121 \\
\hline & $\begin{array}{l}\text { Total modification } \\
\text { group }\end{array}$ & 459 & $46.1 \%$ & $\$ 532$ & $\$ 470$ & $\$ 287$ & 13.79 & 13.00 & 6.01 & 1.59 & 1.00 & 0.99 & 121 & 87 & 107 \\
\hline & Total CCB group & 996 & $100 \%$ & $\$ 475$ & $\$ 436$ & $\$ 243$ & 12.07 & 12.00 & 4.87 & 0.73 & 0.00 & 1.04 & 57 & $\overline{0}$ & 96 \\
\hline
\end{tabular}


In this analysis, increasing the dose was the most common initial modification in the ACEI group and the second most common in the CCB group. A recent survey of treatment trends in hypertension from pharmacy directors in 29 managed care plans revealed interesting results. ${ }^{4}$ They indicated that increasing the dose of either an ACEI or CCB was the most common modification to therapy. They estimated that $27 \%$ and $23 \%$ of patients taking ACEI or CCB, respectively, would increase their dose in the first 12 months of therapy. These percentages are significantly higher that those found in the current analysis ( $16 \%$ and $11 \%$, respectively). In this survey, the respondents indicated that of those patients started on an ACEI, $18 \%$ would switch class, $11 \%$ would switch to another $\mathrm{ACEl}$, and $11 \%$ would add a CCB. For those patients starting on a $C C B$, after increasing the dose the next most common modifications were adding a diuretic (15\%), switching to another $\mathrm{CCB}(13 \%)$, and adding an ACEI (5\%). Again, these findings were significantly different from those found in our analysis. The reason for these differences is not known. However, since this was a survey and not an actual claims analysis, comparing these findings to ours is difficult

Further breakdown of the modification types by the need for subsequent modification is shown in Table 7. Seventy-five percent of the patients in the Increased Dose modification type in both groups had no further modification in therapy, suggesting satisfactory outcome and, one could assume, lower associated medical costs than those requiring additional modifications. The FAC for the Switched Class modification type in the ACEI group was slightly lower ( $\$ 329$ vs. $\$ 340$ ), however. Considering that almost half of these patients required further modification in therapy, thus increasing the need for physician visits, those patients whose initial step was to increase dose likely had lower total medical costs. Because noncompliant patients were excluded from the study, however, these results should be interpreted with caution. The impact that the inclusion of these data would have had on the final numbers is unknown.

Switching $A D$ is considered in patients experiencing a significant adverse event or in those failing to respond to the initial therapy. Switching drugs often is an attempt to simplify a regimen or decrease costs. Such is often the case when patients are switched to a different formulation of the same drug.

In this analysis, switching drugs was subcategorized into three types: Switched Formulation, Switched Class, and Switched Within Class. Each carries a different clinical implication. While Switched Formulation played no role in the ACEI group, it was relatively common with the CCBs ( $0 \%$ vs. $14 \%$ ). In virtually every case, the switch was to a compound dosed less frequently. Almost three-fourths of patients in this category had no further modification to their AD regimen.

Overall, Switched Class was the second most frequent first modification type and, as mentioned earlier, nearly $50 \%$ of

Table 4. Modification Frequency and Associated Antihypertensive Drug Costs

\begin{tabular}{|c|c|c|c|c|c|c|c|c|}
\hline \multirow{2}{*}{$\begin{array}{c}\text { Initial Therapy } \\
\text { Class }\end{array}$} & \multirow{2}{*}{$\begin{array}{c}\text { Number of } \\
\text { Modifications }\end{array}$} & \multirow[t]{2}{*}{ Patient $\mathbf{n}$} & \multicolumn{3}{|c|}{ First Year Acquisition Costs } & \multicolumn{3}{|c|}{ Refill Averages } \\
\hline & & & Mean $\operatorname{Rx} \$$ & Median \$ & Standard Deviation & Mean & Median & Standard Deviation \\
\hline \multirow{8}{*}{ ACEI } & 0 & 554 & $\$ 322$ & $\$ 281$ & $\$ 159$ & 11.244 & 12.000 & 2.133 \\
\hline & 1 & 253 & $\$ 390$ & $\$ 322$ & $\$ 253$ & 12.360 & 12.000 & 4.149 \\
\hline & 2 & 86 & $\$ 477$ & $\$ 412$ & $\$ 296$ & 13.465 & 13.000 & 5.005 \\
\hline & 3 & 24 & $\$ 607$ & $\$ 508$ & $\$ 285$ & 16.167 & 16.500 & 5.395 \\
\hline & 4 & 14 & $\$ 555$ & $\$ 497$ & $\$ 265$ & 15.643 & 13.500 & 4.465 \\
\hline & 5 & 3 & $\$ 609$ & $\$ 602$ & $\$ 94$ & 17.333 & 17.000 & 1.528 \\
\hline & 6 & 2 & $\$ 880$ & $\$ 880$ & $\$ 8$ & 26.500 & 26.500 & 4.950 \\
\hline & & 936 & $\$ 368$ & $\$ 303$ & $\$ 220$ & 11.994 & 12.000 & 3.520 \\
\hline
\end{tabular}

\begin{tabular}{|c|c|c|c|c|c|c|c|c|}
\hline \multirow{2}{*}{$\begin{array}{l}\text { Initial Therapy } \\
\text { Class }\end{array}$} & \multirow{2}{*}{$\begin{array}{c}\text { Number of } \\
\text { Modifications }\end{array}$} & \multirow[t]{2}{*}{ Patient $\mathbf{n}$} & \multicolumn{3}{|c|}{ First Year Acquisition Costs } & \multicolumn{3}{|c|}{ Refill Averages } \\
\hline & & & Mean Rx \$ & Median $\$$ & Standard Deviation & Mean & Median & Standard Deviation \\
\hline \multirow{8}{*}{ CCB } & 0 & 537 & $\$ 427$ & $\$ 414$ & $\$ 186$ & 10.598 & 12.000 & 2.895 \\
\hline & 1 & 300 & $\$ 496$ & $\$ 454$ & $\$ 271$ & 12.730 & 12.000 & 5.196 \\
\hline & 2 & 86 & $\$ 537$ & $\$ 471$ & $\$ 274$ & 13.593 & 13.000 & 4.914 \\
\hline & 3 & 51 & $\$ 649$ & $\$ 564$ & $\$ 333$ & 17.745 & 15.000 & 7.957 \\
\hline & 4 & 12 & $\$ 708$ & $\$ 576$ & $\$ 347$ & 19.083 & 14.500 & 9.596 \\
\hline & 5 & 5 & $\$ 629$ & $\$ 645$ & $\$ 264$ & 17.600 & 17.000 & 5.594 \\
\hline & 6 & 5 & $\$ 861$ & $\$ 842$ & $\$ 153$ & 24.000 & 24.000 & 4.062 \\
\hline & & 996 & $\$ 475$ & $\$ 436$ & $\$ 243$ & 12.069 & 12.000 & 4.868 \\
\hline
\end{tabular}


these patients had a subsequent modification. The reason for this high rate of subsequent modifications is unknown.

However, switching to a new class is, in essence, like starting anew, with the subsequent need for modifications. Patients in this group who did not have subsequent modification had an FAC at or below the patients in the No Modification category.

The therapeutic rationale for switching a drug within the same class, especially in the case of the ACEIs, is limited. While this occurred in very few patients in the ACEI group, nearly $5 \%$ of the patients who started on a CCB switched within the class. Because of the differing physiologic effect and adverse event profile of drugs within this class, specifically when considering the dihydropyridines versus the nondihydropyridines, it seems a logical alternative for those with inadequate initial response to therapy. As with patients in the
Switched Class category, a large percentage of these patients required further modification to their regimen. The FACs for patients in this category were relatively low, especially in the CCB group.

Added Drug (New Class) was the third most common modification type overall. Much attention has been placed recently on the use of combination therapy, specifically the combination of drugs resulting in a synergistic effect on blood pressure. This often allows the use of lower doses of both products to achieve the same, if not better, blood pressure response and decrease the incidence of adverse events. In this analysis, the most common addition to an ACEI was a CCB and the most common addition to a CCB was an ACEI: The rationale for this combination is strong, as evidenced by the large number of fixed-dose combination products currently on

Table 5. Frequency of Each Modification Type by Month for First Year

\begin{tabular}{|c|c|c|c|c|c|c|c|c|c|}
\hline $\begin{array}{l}\text { Initial } \\
\text { Therapy } \\
\text { Class }\end{array}$ & Month & $\begin{array}{l}\text { Changed } \\
\text { Dose } \\
\text { (Increase) }\end{array}$ & $\begin{array}{l}\text { Changed } \\
\text { Dose } \\
\text { (Decrease) }\end{array}$ & $\begin{array}{l}\text { Added Drug } \\
\text { (New Class) }\end{array}$ & \begin{tabular}{|c|} 
Added Drug \\
(Same \\
Class)
\end{tabular} & $\begin{array}{c}\text { Changed } \\
\text { Drug (Form. } \\
\text { Within } \\
\text { Class) }\end{array}$ & $\begin{array}{l}\text { Changed } \\
\text { Drug } \\
\text { (Within } \\
\text { Class) }\end{array}$ & $\begin{array}{l}\text { Changed } \\
\text { Drug (Diff. } \\
\text { Class) }\end{array}$ & $\begin{array}{l}\text { Patient } \\
\text { Totals }\end{array}$ \\
\hline \multirow{13}{*}{ ACEI } & 1 & 30 & 6 & 40 & 1 & 0 & 0 & 14 & 91 \\
\hline & 2 & 27 & 5 & 13 & 0 & 0 & 2 & 17 & 64 \\
\hline & 3 & 20 & 4 & 7 & 0 & 0 & 4 & 14 & 49 \\
\hline & 4 & 14 & 5 & 6 & 0 & 0 & 1 & 11 & 37 \\
\hline & 5 & 12 & 1 & 4 & 0 & 0 & 0 & 6 & 23 \\
\hline & 6 & 6 & $\mathrm{l}$ & 3 & 0 & 0 & 0 & 6 & 16 \\
\hline & 7 & 14 & 0 & 2 & 1 & 0 & 2 & 7 & 26 \\
\hline & 8 & 5 & 1 & 2 & 1 & 0 & 1 & 3 & 13 \\
\hline & 9 & 8 & 3 & 1 & 0 & 0 & 2 & 8 & 22 \\
\hline & 10 & 5 & 2 & 1 & 0 & 0 & 1 & 6 & 15 \\
\hline & 11 & 5 & 2 & 0 & 0 & 0 & 1 & 6 & 14 \\
\hline & 12 & 7 & 1 & 0 & 0 & 0 & 0 & 4 & 12 \\
\hline & Total & 153 & 31 & 79 & 3 & 0 & 14 & 102 & 382 \\
\hline
\end{tabular}

\begin{tabular}{|c|c|c|c|c|c|c|c|c|c|}
\hline $\begin{array}{l}\text { Initial } \\
\text { Therapy } \\
\text { Class }\end{array}$ & Month & $\begin{array}{l}\text { Changed } \\
\text { Dose } \\
\text { (Increase) }\end{array}$ & $\begin{array}{l}\text { Changed } \\
\text { Dose } \\
\text { (Decrease) }\end{array}$ & $\begin{array}{l}\text { Added Drug } \\
\text { (New Class) }\end{array}$ & $\begin{array}{c}\text { Added Drug } \\
\text { (Same } \\
\text { Class) }\end{array}$ & $\begin{array}{l}\text { Changed } \\
\text { Drug (Form. } \\
\text { Within } \\
\text { Class) }\end{array}$ & $\begin{array}{l}\text { Changed } \\
\text { Drug } \\
\text { (Within } \\
\text { Class) }\end{array}$ & $\begin{array}{l}\text { Changed } \\
\text { Drug (Diff. } \\
\text { Class) }\end{array}$ & $\begin{array}{l}\text { Patient } \\
\text { Totals }\end{array}$ \\
\hline \multirow{13}{*}{ CCB } & 1 & 21 & 1 & 59 & 2 & 14 & 7 & 22 & 126 \\
\hline & 2 & 15 & 3 & 15 & 1 & 7 & 10 & 13 & 64 \\
\hline & 3 & 9 & 2 & 11 & 1 & 5 & 7 & 8 & 43 \\
\hline & 4 & 12 & 5 & 13 & 0 & 5 & 3 & 6 & 44 \\
\hline & 5 & 13 & 4 & 0 & 0 & 3 & 4 & 2 & 26 \\
\hline & 6 & 6 & 2 & 4 & 0 & 4 & 6 & 4 & 26 \\
\hline & 7 & 7 & 0 & 5 & 0 & 6 & 1 & 9 & 28 \\
\hline & 8 & 6 & 2 & 3 & 0 & 3 & 2 & 4 & 20 \\
\hline & 9 & 1 & 1 & 3 & 0 & 6 & 4 & 5 & 20 \\
\hline & 10 & 3 & 1 & 2 & 0 & 7 & 2 & 6 & 21 \\
\hline & 11 & 3 & 3 & 1 & 1 & 1 & 2 & 7 & 18 \\
\hline & 12 & 10 & 1 & 0 & 0 & 2 & 3 & 7 & 23 \\
\hline & Total & 106 & 25 & 116 & 5 & 63 & 51 & 93 & 459 \\
\hline
\end{tabular}


the market or in clinical development. As one would expect, the use of this combination resulted in the highest FAC among all categories. This would strengthen the case further for the fixed-dose combination ACEI/CCB products, since the cost of the fixed-dose products is less than many of the drugs in the CCB category alone.

There are certainly weaknesses to these assumptions. Without close examination of the medical record, blood pressure values cannot be determined to assure that the patient is at target. While it is more likely that patients in the no-modification group were well controlled, it is obviously not a certainty. Additionally, target blood pressure is defined by the PCP and is not necessarily the same as those set by national committees (i.e., <140/90 mm Hg). ${ }^{3}$

\section{CONCLUSION}

This LPR analysis strongly suggests that unsatisfactory outcomes in the management of hypertensive patients, defined as an increase in the number of AD modifications, lead to an increase in health care costs. While these data offer insight into the therapeutic process and decision making of the prescriber, additional work needs to be done. Incorporating additional outcomes data, such as clinical results and level of blood pressure control achieved with each modification type and frequency, is a needed dimension for this model building. A complete economic model also should take into account the additional direct costs of any increased ambulatory services, such as diagnostic services, as well as related hospitalizations.

Note also that the inclusion of data from noncompliant patients would potentially have an impact on the conclusions of this study, the most obvious being the modification rate. The modification rate would likely increase, since noncompliance typically leads to an unsuccessful outcome-namely not reaching target blood pressure levels.

The results from this LPR analysis do offer a strong base on which to further develop a useful economic model for hypertension therapies in the office setting. Relating the clinical explanations of therapeutic failure to the economic results as shown in the pharmacy claims data points to potential cost savings in formulary design and to improved patient outcomes. The results found here suggest that increasing the dose

Table 6. Pre- and Post-Modification Costs per Member per Month

\begin{tabular}{|c|c|c|c|c|c|c|c|}
\hline \multirow[t]{2}{*}{ Initial Therapy Class } & \multirow[t]{2}{*}{ Event } & \multicolumn{3}{|c|}{ Pre-modification PMPM } & \multicolumn{3}{|c|}{ Post-modification PMPM } \\
\hline & & Mean & Median & SD & Mean & Median & SD \\
\hline \multirow{10}{*}{ ACEI } & No modification & $\$ 25$ & $\$ 22$ & $\$ 12$ & & & \\
\hline & Increased dose & $\$ 22$ & $\$ 19$ & $\$ 13$ & $\$ 30$ & $\$ 25$ & $\$ 14$ \\
\hline & Decreased dose & $\$ 23$ & $\$ 19$ & $\$ 18$ & $\$ 31$ & $\$ 23$ & $\$ 17$ \\
\hline & Added drug (new class) & $\$ 29$ & $\$ 24$ & $\$ 16$ & $\$ 55$ & $\$ 51$ & $\$ 31$ \\
\hline & Added drug (same class) & $\$ 18$ & $\$ 15$ & $\$ 11$ & $\$ 23$ & $\$ 23$ & $\$ 14$ \\
\hline & Switched formulation & & & & & & \\
\hline & Switched within class & $\$ 33$ & $\$ 28$ & $\$ 18$ & $\$ 28$ & $\$ 25$ & $\$ 11$ \\
\hline & Switched class & $\$ 22$ & $\$ 19$ & $\$ 13$ & $\$ 36$ & $\$ 32$ & $\$ 16$ \\
\hline & Total modification group & $\$ 24$ & $\$ 20$ & $\$ 15$ & $\$ 37$ & $\$ 29$ & $\$ 22$ \\
\hline & Total ACE group & $\$ 24$ & $\$ 20$ & $\$ 15$ & $\$ 30$ & $\$ 24$ & $\$ 18$ \\
\hline
\end{tabular}

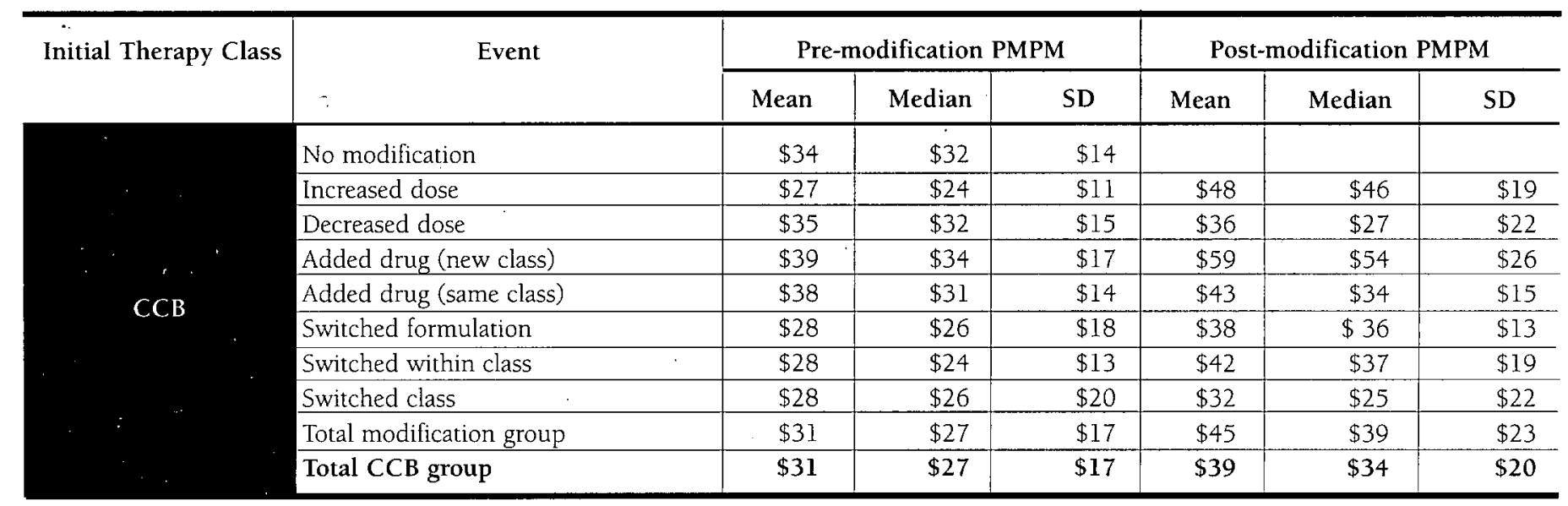


The Clinical and Economic Implications of Drug Utilization Patterns in the Treatment of Hypertension with ACE Inhibitors and Calcium Channel Blockers in a Managed Care Setting

Table 7. Only One Modification Patients

\begin{tabular}{|c|c|c|c|c|c|c|c|}
\hline \multirow{2}{*}{$\begin{array}{c}\text { Initial Therapy } \\
\text { Class }\end{array}$} & \multirow[t]{2}{*}{ Event } & \multicolumn{2}{|c|}{ First Modification } & \multirow{2}{*}{$\frac{\text { FAC }}{\text { Mean \$ }}$} & \multicolumn{2}{|c|}{ No Additional Modifications } & \multirow{2}{*}{$\frac{\text { FAC }}{\text { Mean \$ }}$} \\
\hline & & $\mathbf{n}$ & $\%$ & & $\mathbf{n}$ & $\%$ & \\
\hline \multirow{8}{*}{ ACEI } & lncreased dose & 153 & $40 \%$ & $\$ 357$ & 115 & $75 \%$ & $\$ 340$ \\
\hline & Decreased dose & 31 & $8 \%$ & $\$ 378$ & 22 & $71 \%$ & $\$ 329$ \\
\hline & Added drug (new class) & 79 & $21 \%$ & $\$ 670$ & 48 & $61 \%$ & $\$ 627$ \\
\hline & Added drug (same class) & 3 & $1 \%$ & $\$ 274$ & 2 & $67 \%$ & $\$ 288$ \\
\hline & Switched formulation & 0 & $0 \%$ & $\$ 0$ & 0 & $0 \%$ & $\$ 0$ \\
\hline & Switched within class & 14 & $4 \%$ & $\$ 331$ & 12 & $86 \%$ & $\$ 355$ \\
\hline & Switched class & 102 & $27 \%$ & $\$ 402$ & 53 & $52 \%$ & $\$ 329$ \\
\hline & Total & 382 & $100 \%$ & $\$ 434$ & 252 & $66 \%$ & \\
\hline
\end{tabular}

\begin{tabular}{|c|c|c|c|c|c|c|c|}
\hline \multirow{2}{*}{$\begin{array}{c}\text { Initial Therapy } \\
\text { Class }\end{array}$} & \multirow[t]{2}{*}{ Event } & \multicolumn{2}{|c|}{ First Modification } & \multirow{2}{*}{$\frac{\text { FAC }}{\text { Mean } \$}$} & \multicolumn{2}{|c|}{ No Additional Modifications } & \multirow{2}{*}{$\frac{F A C}{\text { Mean } \$}$} \\
\hline & & $\mathbf{n}$ & $\%$ & & $\mathbf{n}$ & $\%$ & \\
\hline \multirow{8}{*}{ CCB } & Increased dose & 106 & $23 \%$ & $\$ 531$ & 80 & $75 \%$ & $\$ 504$ \\
\hline & Decreased dose & 25 & $5 \%$ & $\$ 465$ & 16 & $* 64 \%$ & $\$ 393$ \\
\hline & Added drug (new class) & 116 & $25 \%$ & $\$ 732$ & 77 & $66 \%$ & $\$ 708$ \\
\hline & Added drug (same class) & 5 & $1 \%$ & $\$ 539$ & 5 & $* 100 \%$ & $\$ 539$ \\
\hline & Switched formulation & 63 & $14 \%$ & $\$ 452$ & 45 & $71 \%$ & $\$ 437$ \\
\hline & Switched within class & 51 & $11 \%$ & $\$ 483$ & 29 & $57 \%$ & $\$ 384$ \\
\hline & Switched class & 93 & $20 \%$ & $\$ 384$ & 47 & $51 \%$ & $\$ 300$ \\
\hline & Total & 459 & $100 \%$ & $\$ 532$ & 299 & $65 \%$ & \\
\hline
\end{tabular}

* Sample sizes too small to interpret with accuracy.

of an ACEI or CCB or moving the patient more quickly to combination therapies are logical first steps and have an acceptable rate of subsequent modification. These results seem to support the recently published guidelines for the management of hypertension from the Joint National Committee. ${ }^{5}$ The use of combination therapy is even more attractive when considering that fixed combinations of ACEIs and CCBs are often less expensive than single-drug products. Other options such as changing the formulation of a product dosed less frequently to increase patient compliance also are valuable alternatives.

In this analysis, switching the class of ADs seemed to be the least successful alternative, at least in terms of requiring future modifications to AD therapy. As suggested by these data, optimizing the use of medications in the managed care setting by reducing the number of therapeutic modifications necessary to achieve appropriate blood pressure control in the patient is possible. The resulting cost savings due to reduced direct medical costs associated with these modifications and the better outcome due to reaching patient goals more quickly are both desirable in the managed care setting.
References

1. Burt VL, Whelton P, Roccella EJ, et al. Prevalence of hypertension in the US adult population. Results from the Third National Health and Nutrition Examination Survey, 1988-1991 Hypertens 1995; 25: 305-13.

2. American Heart Association 1997 Heart \& Stroke Statistical Update. Dallas, TX: American Heart Association, 1996.

3. Joint National Committee on Detection, Evaluation and Treatment of High Blood Pressure: The fifth report of the Joint National Committee on Detection, Evaluation and Treatment of High Blood Pressure (JNC V). Arch Intern Med 1993; 153: 154-83

4. Bobal E, O'Connor DL, Keefe J. Trends in the treatment of hypertension within managed care organizations: A national survey of HMO pharmacy directors. JMCP 1997; 3: 317-22.

5. Joint National Committee on the Prevention, Detection, Evaluation, and Treatment of High Blood Pressure. The sixth report of the Joint National Committee on the Prevention, Detection, Evaluation, and Treatment of High Blood Pressure. Arch Intern Med 1997;157: 2413-46. 